\title{
Current Concept Management of Carpal Tunnel Syndrome: A Case Report
}

\author{
Pamudji Utomo, Wan Adi Surya, Seti Aji Hadinoto, Tito Sumarwoto \\ Department of Orthopaedics and Traumatology, Prof. Dr. R. Soeharso Orthopaedics Hospital/ \\ Faculty of Medicine, Universitas Sebelas Maret
}

Background: Carpal Tunnel Syndrome (CTS) is the most common median nerve compression neuropathy. CTS presents in $3.8 \%$ of the general population, affecting female more than male. CTS can be clinically or surgically treated, based on the severity of the disease. This study aimed to reported current concept management of carpal tunnel syndrome.

Case Presentation: A 48 years old female presents with history of numbness on her left hand since 1 year ago, which were preceded by pain on her wrist. Her symptoms are worse at night, she often awakes because of the pain, and she shakes her hands for relief. The numbness was getting worse when she was working with her left hand. She also felt progressive decrease of sensation on her left hand. No systemic symptoms are noted. On examination, there is obvious thenar muscles atrophy on her left hand. There is no weakness on motoric examination. Wrist and finger range of motion are within normal limit. She felt tingling sensation on her 3 radial digits with Tinel and Phalen maneuvers.

Results: Non-operative treatments, like splinting, corticosteroid injection, exercise, and oral medication are still widely used and effective to reduce symptoms of CTS. For operative treatment, OCTR still become a standard treatment of severe CTS.

Conclusion: Carpal tunnel syndrome management can be done by operative or non-operative treatments.

Keywords: Carpal Tunnel Syndrome

\section{Correspondence:}

Pamudji Utomo. Department of Orthopaedics and Traumatology Prof. Dr. R.Soeharso Orthopaedics Hospital, Surakarta. Email: utomodr@yahoo.com.

Cite this as:

Utomo P, Surya WA, Hadinoto SA, Sumarwoto T (2020). Current Concept Management of Carpal Tunnel Syndrome: A Case Report. Indones J Med. 05(01): 70-86. https://doi.org/10.26911/theijmed.2020.05.01.11

cc) (7) (2) Indonesian Journal of Medicine is licensed under a Creative Commons

Attribution-NonCommercial-ShareAlike 4.o International License.

\section{BACKGROUND}

Carpal Tunnel Syndrome (CTS) is a symptomatic compression neuropathy of the median nerve at the level of the wrist, characterized physiologically by evidence of increased pressure within the carpal tunnel and decreased function of the nerve at that level (Seiler, 2002; American Academy of Orthopaedic Surgeons Work Group Panel, 2007). CTS is the most well-known median nerve entrapment, and accounts for $90 \%$ of all entrapment neuropathies. An entrapment neuropathy is achronic focal compressive neuropathy caused by a pressure increase inside non-flexible anatomical structures (Martins and Siqueira, 2017). In the normal carpal tunnel there is barely room for all the tendons and the median nerve; consequently, any swelling is likely to result in compression and ischemia of the nerve (Blom et al., 2017). Carpal Tunnel Syndrome was firstly described by Paget, back in 1854, who reported a case of patient with symptom of median nerve compression following fracture of distal radius (Paget, 2007).

The carpal bones are arranged to form the base and sides of an arch-shaped tunnel. The flexor retinaculum, or transverse carpal 
ligament, is a fibrous band that attaches the medial and lateral eminences of these bones arch, forming the palmar roof of a narrow opening called the carpal tunnel (Chammas et al., 2014; Martins and Siqueira, 2017). The median nerve is accompanied by four tendons from the superficial flexors of the fingers, four tendons from the deep flexors of the fingers and the long flexor of the thumb. The long flexor of the thumb is the most radial element (Chammas et al., 2014). Most cases of CTS are idiopathic. Secondary causes of CTS include the following: space-occupying lesions (tumors, hypertrophic synovial tissue, fracture callus, and osteophytes), metabolic and physiologic conditions (pregnancy, hypothyroidism, and rheumatoid arthritis), infections, neuropathies (associated with diabetes mellitus or alcoholism), and familial disorders (Seiler, 2002; Uchiyama et al., 2010; Ashworth, 2016; Bloom et al., 2017).

CTS is the most frequent entrapment neuropathy, believed to be present in $3.8 \%$ of the general population, affecting female more than male (Ibrahim et al., 2012). The prevalence of CTS among the population is between $4 \%-5 \%$, particularly affecting individuals between 40 and 60 years of age (Chammas et al., 2014). In United State, the prevalence of CTS is 5\% (American Academy of Orthopaedic Surgeons Work Group Panel,
2007). In Indonesia, a study conducted by Andrian et al. (2017), showed that the prevalence of CTS among administrative worker at Hasan Sadikin General Hospital Bandung is $3.3 \%$.

\section{CASE PRESENTATION}

A 48 years old female presents with history of numbness on her left hand since 1 year ago, which was preceded by pain on her wrist. Her symptoms are worse at night, she often awakes because of the pain, and she shakes her hands for relief. The numbness was getting worse when she was working with her left hand. She also felt progressive decrease of sensation on her left hand.No systemic symptoms are noted. On examination, there is obvious thenar muscles atrophy on her left hand. There is no weakness on motoric examination. Wrist and finger range of motion are within normal limit. She felt tingling sensation on her 3 radial digits with Tinel and Phalen maneuvers.

\section{RESULTS}

Figure 1 showed a left hand of 48 years old female patient with advanced CST and atrophy of the thenar muscles are clearly seen on inspection (arrow). She was a patient at Department of Orthopaedic and Traumatology, Prof. Dr. R. Soeharso Orthopaedics Hospital, Surakarta, Central Java, Indonesia.

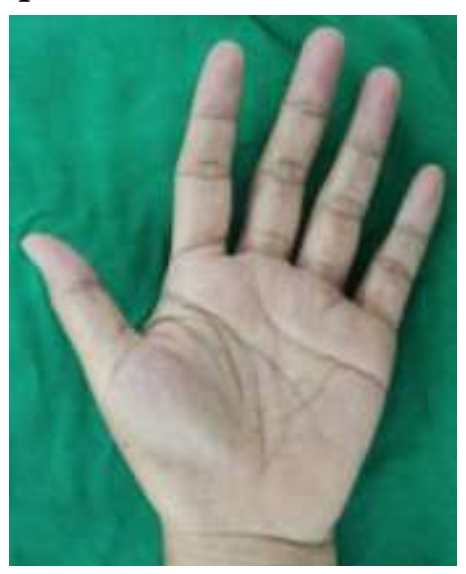

Figure 1. Left hand of 48 years old female patient with advanced CST, atrophy of the thenar muscles are clearly seen on inspection (arrow) 
Non-operative treatments, like splinting, corticosteroid injection, exercise, and oral medication are still widely used and effective to reduce symptoms of CTS. For operative treatment, OCTR still become a standard treatment of severe CTS. However, OCTR procedure provides some complications, such as long wound healing and hand function recovery due to big incision, even it ends up with good clinical outcome. ECTR is still debatable on fact that surgeons have to insert cannula into already high pressured tunnel, even it is an useful technique for releasing pressure in carpal tunnel. MiniOCTR is modification of OCTR with much smaller incision size. The idea is to reduce surrounding soft tissue trauma and postoperative complication.

\section{DISCUSSION}

Carpal Tunnel Syndrome is characterized by pain, paresthesia, or numbness at distal distribution of median nerve, including palmar part of the thumb, index finger, middle finger, and radial part of ring finger (Ibrahim et al., 2012; Wipperman and Goerl, 2015). Symptom felt mostly at night, or during the day with lots of activities at wrist (flexion or extension) (Ibrahim et al., 2012; Chammas et al., 2014; Padua et al., 2016). This symptom is usually localized at the wrist or 3.5 radial digit of hand, but in severe or late case, it can radiate proximally to forearm, upper arm, and sometime to shoulder. Patients with CTS often shake off their wrist to relieve the symptom, known as flick sign. Flick sign is 93\% sensitive and 96\% specific for CTS (Ibrahim et al., 2012; Wipperman and Goerl, 2015). In mild to moderate CTS patient, the symptoms (pain or paresthesia) are more dominant than hand functional limitation. As the disease gets more severe, patients feel less severe symptoms, but more limited function of the hand (Ibrahim et al., 2012; Padua et al., 2016). In severe compression of median nerve, sensory function will be impaired so those patients feel more numbness than pain and paresthesia (Ibrahim et al., 2012). Loss of pain sensation, hand muscle weakness, and thenar muscles atrophy are late findings in CTS, mean permanent sensory loss and motoric impairment due to extensive axonal damage (Ibrahim et al., 2012; Wipperman and Goerl, 2015; Padua et al., 2016).

In mild to moderate CTS patients, physical finding can be normal, but inspection of the hand and wrist needed to be done to evaluate predisposing factors, such as sign of previous injury of deformity due to trauma or arthritis (Wipperman and Goerl, 2015). In more severe case, sensory and motoric impairment can be found (Ibrahim et al., 2012; Wipperman and Goerl, 2015). Patients may feel numbness at distal part of median nerve distribution (3.5 radial hand) and decreasing ability of two point discrimination (Wipperman and Goerl, 2015). Function of thumb abduction and opposition can be tested to determined motoric impairment in advance CTS (Padua et al., 2016; Wipperman and Goerl, 2015). In advance case, patient may have no symptoms, but hand weakness and thenar muscle atrophy are dominant (Ibrahim et al., 2012; Uchiyama et al., 2010; Wipperman and Goerl, 2015).

There are some test can use to examine patients with CTS symptom. These most popular test are Phalen's test and Tinel's test (Padua et al., 2016). In positive Tinel's test patient feels pain or paresthesia at median nerve distribution when palmar side of wrist is being manually percussed. Phalen's test is done by ask patient to actively flexed the wrist for 1 minute. Pain or paresthesia appears on median nerve are if the test is positive (Chammas et al., 2014; Padua et al., 2016). These tests are easy to perform, and positive result of these increases the probability of CTS (Wipperman and Goerl, 2015). 
Another test that can be performed in CTS patient is carpal tunnel compression test. The test is performed by applying pressure on median nerve region of carpal tunnel, with the wrist at 600 of flexion. It is positive if patient feel pain or tingling at median nerve distribution (Uchiyama et al., 2010; Chammas et al., 2014). Other provocation test is hand elevation maneuver. The patient is asked to raise their affected hand above the head for 1 minute. The test is positive when pain or tingling appears on median nerve innervation area (Uchiyama et al., 2010; Chammas et al., 2014; Wipperman and Goerl, 2015). When patient hold their affected hand arise, it will reduce blood supply on already diseased median nerve, worsen nerve condition so that the symptom appears (Uchiyama et al., 2010).

\section{Non-operative Treatment a. Splinting}

For patients with mild CTS symptoms, the simplest treatment is a night splint. Splint- ing has the advantage of being inexpensive and is associated with a minimal complication rate (Seiler; 2002; Wipperman and Goerl, 2015; Blomet al., 2017). As CTS has been associated with forceful, repetitive hand and wrist activities, one purpose of splinting is to minimize motion at the wrist and subsequently decrease symptoms of pain and/or numbness (Carlson et al, 2010). The other reason for splinting was established based on the following: avoiding the extremes of wrist position reduces the pressure within the carpal tunnel and the neutral wrist position improves hemodynamic parameters, reducing the edema and minimizing nerve friction and compression (Wipperman and Goerl, 2015; Martins and Siqueira, 2017). In 2014, Halac et.al, following 40 patients with regular splinting compliance showed result that splinting is effective in reducing nocturnal pain in CTS (Halac et al., 2015).

\section{Figure 2. Example of splint for carpal tunnel syndrome (Halac et al., 2015)}

\section{b. Corticosteroid Injection}

Corticosteroid injection is used in the conservative treatment of CTS to reduce symptoms (Seiler, 2002; Blom et al., 2017; Martins and Siqueira, 2017), even the exact mechanism of this therapy remains unclear but the antiinflammatory effect is probably the most significant factor (Martins and Siqueira, 2017). Steroids are able to reduce edema, improving the spatial relation between the carpal tunnel and the median nerve and tendons (Padua et al., 2016). In a randomized trial of 111 patients, injection of $80 \mathrm{mg}$ methylprednisolone and $40 \mathrm{mg}$ methyl 
prednisolone into the carpal tunnel was more effective than placebo, reducing symptoms severity and rate of surgery at 1 year (Atroshi et al., 2013).

Although corticosteroid treatment is generally safe and effective in reducing the symptom, there is risk of median nerve injury and tendon rupture. Steroids inhibit tenocyte function by reducing synthesis of collagen and proteoglycan, thus reducing the mechanical strength of the tendon causingto further degeneration (Uchiyama et al., 2010). Ultrasound guided injection may be more effective than blind injection, allowing direct visualization to ensure accurate and safe needle placement (Lee et al., 2014). In a meta-analysis of 10 studies with 633 patients conducted by Chen et al. (2015), local corticosteroid injections using the ultrasound-guided inplane injection (Ulnar-I) approach was the best treatment strategy for clinical response, change in symptom severity scale, and functional status scale at short-term followup period (Chen et al., 2015).

In another study, conducted by Chesterton et al. (2018), that comparing local corticosteroid injection with night-rest splinting showed that at 6 weeks, across all primary and secondary outcome, single injection $20 \mathrm{mg}$ methylprednisolone acetate has greater improvements in pain and function than night splints. A prospective study by Blazar et al. (2015) evaluate recurrent probability after single injection of steroid in CTS patients showed that that $79 \%$ of patients with carpal tunnel syndrome had resolved symptoms six weeks after a corticosteroid injection, $53 \%$ remained symptom-free at six months, and $31 \%$ remained symptom-free at one year.

\section{c. Ultrasound Therapy}

The AAOS guideline recommends ultrasound treatment for CTS (American Academy of Orthopaedic Surgeons Work Group Panel, 2007). Ultrasound treats CTS by directing high-frequency sound waves at the inflamed area. The sound waves are converted into heat in the deep tissues of the hand, and are presumed to open the blood vessels, allowing oxygen to be delivered to the injured tissue, subsequently may accelerate the healing process in damaged tissues (Ono et al., 2010; Carlson et al., 2010). Deep, pulsed ultrasound over the carpal tunnel for $15 \mathrm{~min}$ for 20 treatments decreases pain and paresthesia symptoms, reduces sensory loss, and improves median nerve conduction and strength (Carlson et al., 2010). A randomized trial study conducted by Chang et al. showed that combination of ultrasound therapy with orthosis/splinting is effective in improving functional status of CTS patients. In addition, in this study found that combination of ultrasound therapy with a wrist orthosis may be more effective than paraffin therapy with a wrist orthosis (Chang et al., 2014). In another study conducted by Ahmed et al. (2017), comparing Low Level Laser Therapy (LLLT) and Ultrasound (US) in treatment of CTS showed that both, LLLT and US are effective in the treatment of mild and moderate CTS patients.

\section{d. Oral Medication}

Oral steroid has been suggested by AAOS guideline for CTS management with moderate recommendation (American Academy of Orthopaedic Surgeons Work Group Panel, 2007). Oral prednisone at a dosage of $20 \mathrm{mg}$ daily for 10 up to 14 days improves symptoms and function compared with placebo (Wipperman and Goerl, 2015).

AAOS Guideline for CTS management also found moderate evidence that supports there is no benefit of oral treatments (diuretic, gabapentin, astaxanthin capsules, NSAIDs, or pyridoxine) for CTS compared to placebo (American Academy of Orthopaedic Surgeons Work Group Panel, 2007; Ono et al., 2010), but in clinical trial conducted by Sabet et al. (2017) showed that naproxen as a 
NSAIDS was caused reduction of pain during two-month treatment. Combination therapy between (gabapentin + naproxen) were more effective for patients with mild CTS. Even not recommended by AAOS guideline, vitamin B6 (pyridoxine) is still used for CTS therapy with dosage of $200 \mathrm{mg}$ daily. The rationale is vitamin B6 (pyridoxine) acts as a coenzyme in numerous enzymatic reactions of lipid, amino acids and glucose metabolism that are part of the neural function (Martins and Siqueira, 2017).

Talebi et al. (2013) showed that vitamin B6 treatment improves clinical symptoms and sensory electro diagnostic results in CTS patients.

\section{e. Exercise}

Mobilization exercises are commonly used for symptoms of CTS by improving axonal transport and nerve conduction. The exercise that usually done was tendon gliding and nerve gliding exercises. Tendon and nerve gliding exercises may maximize the relative excursion of the median nerve in the carpal tunnel and the excursion of the flexor tendons relative to one another (Carlson et al., 2010).

The exercises are a sequence of finger movements, for tendon gliding, and wrist and fingers movements, for median nerve gliding. Patients have to practice each exercise, ten in repetitions, three to five times each day. Each position was held for five seconds (Martins and Siqueira, 2017).

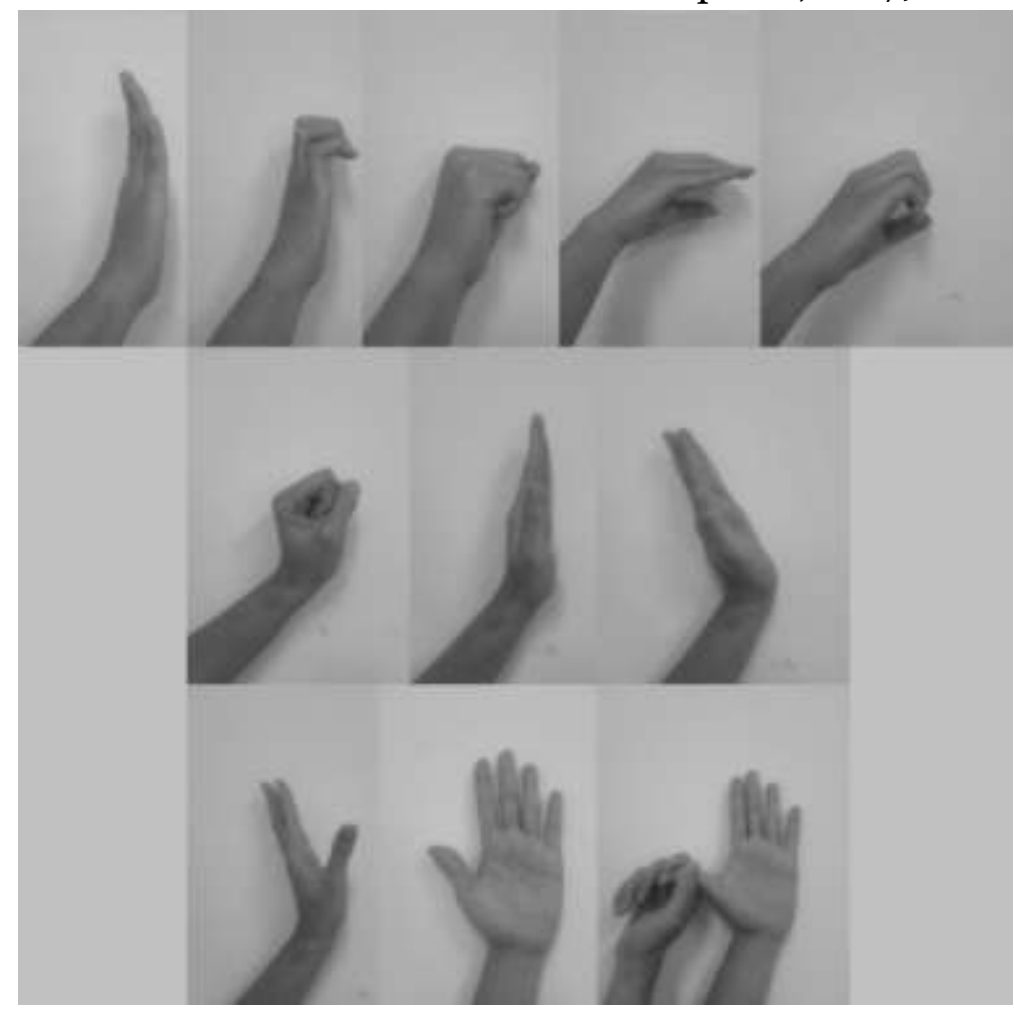

\section{Figure 3. (A) Example of finger movements in tendon gliding exercises (B) Finger movements during median nerve gliding exercises}

Page et al. (2012) make a review about some studies about exercise or mobilization intervention in people with CTS concluded that there was only limited and very low quality evidence that support effectiveness of exercise and mobilisation interventions for CTS. Ashworth (2016), stated that nerve and tendon gliding exercises were less effective than splinting in reducing symptoms and improving hand function in patient with CTS. 


\section{Surgical Treatment}

AAOS guideline recommends that if conservative treatment unable to reduce patient's symptoms within 2-7 weeks, physicians should start to consider another non-operative treatment or surgery (American Academy of Orthopaedic Surgeons Work Group Panel, 2007; Uchiyama et al., 2010; Ono et al., 2010). Currently, surgery is more effective than conservative treatment (Uchiyama et al., 2010). The aim of surgical treatment is to reduce pressure to median nerve in the carpal tunnel by increasing the space of the carpal tunnel, by transecting the transverse carpal ligament (Chammas et al., 2014; Ghasemi-rad et al., 2014; Padua et al., 2016). Surgery is recommended for patients with moderate to severe CTS (Ghasemi-rad et al., 2014). There are several methods of CTR surgery. The two major types are Open Car- pal Tunnel Release (OCTR) and Endoscopic Carpal Tunnel Release (ECTR) (Uchiyama et al., 2010; Ono et al., 2010; Chammas et al., 2014; Padua et al., 2016). The OCTR procedure can be further classified into full/ extended-open and mini-open with a one inch incision, new incision techniques of OTCR (Ono et al., 2010; Ghasemi-rad et al., 2014; Padua et al., 2016). All the techniques are done under loco regional or local anesthesia and using tourniquet (Chammas et al., 2014).

a. Anatomical variations of median nerve motor branch

A thorough knowledge of the normal and variant anatomy of the median nerve in the wrist is important to avoid complications during surgery. Lanz classified the variations of the course of the median nerve into four groups (Demicray et al., 2011):

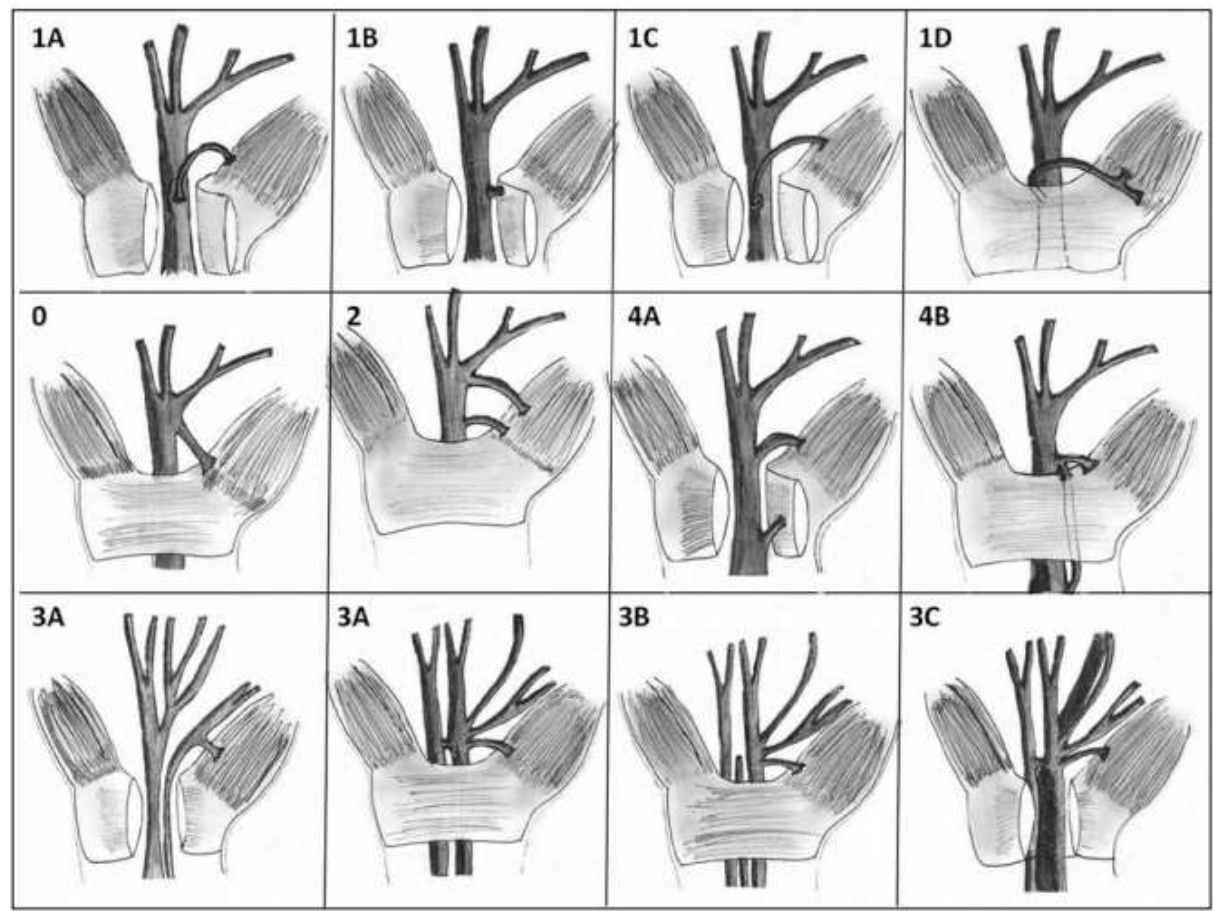

Figure 4. Lanz's classification of the median nerve anatomical variations at the wrist. Group I, Thenar branch variations; 1A: subligamentous; 1B:

transligamentous; 1C:ulnar wards; 1D:supraligamentous. Group o,extraligamentous thenar branch. Group II, distal accessory thenar branch. Group IV,proximal accessory thenar branch; 4A:running directly in the thenar muscles; 4B:joining another branch. Group III,high division of the median nerve; 3A:without an artery of muscle; 3B:with artery; $3 \mathrm{C}$ :with lumbrical muscle 
1) Group O: Extraligamantous thenar branch (standard anatomy),

2) Group I: Variations in the course of the thenar branch, divided into 4 sub-groups:

a) Group I a, the motor branch of the median nerve starts beneath the transverse ligament and then bends around its distal edge (sub ligamentous).

b) Group I b, the motor branch originates from the radial side of the median nerve and then passes through the transverse ligament (transligamentous).

c) Group I c, the motor branch arises from the ulnar side of the median nerve.

d) Group I d, the motor branch bends around the distal edge of the ligament (supraligamentous)

3) Group II: Accessory branches of the median nerve at the distal portion of the carpal tunnel,

4) Group III: High divisions of the median nerve, divided in to three subgroups:

a) Group III a: absence of amedian artery between the two branches

b) Group III b: presence of a median artery between the two branches

c) Group III c: presence of an accessory lumbrical muscle between the two branches of the proximally divided median nerve

5) Group IV: Accessory branches proximal to the carpal tunnel,

a) Group IV a: accessory thenar branchrun directly in the thenar muscles,

b) Group IV b: accessory thenar branch join another motor branch first before run into thenar muscle (Demicray et al., 2011).

\section{b. Kaplan's cardinal line and its clini- cal application on safety in surgical incision}

The precision in incision used in CTR is important in preventing iatrogenic injury and ensuring a good outcome. The limited visual field in CTR, especially in the endoscopic method, attention to the important topogra- phical marker is needed to predict underlying structures. The most vulnerable structure during CTR is the superficial palmar arch. To make sure that skin incision that is made for CTR is in relative safe zone, surgeon need to understand the structure in SPA and its relationships to surface markers. Kaplan's cardinal line, firstly described in 1953 by E.B. Kaplan, is one of the most notable surface markers. Kaplan's description of his landmark as a line drawn from the apex of the inter-digital fold between the thumb and index finger toward the ulnar side of the hand, parallel with the middle crease of the hand (Panchal and Trzeciak, 2010).

Some studies say that KCL is surface marker representing the motor branch of the median nerve, deep branch of ulnar nerve, distal extent of the transverse carpal ligament, and the SPA so it becomes important to accurately define the landmark. KCL also represents an accurate surface marker for the deep palmar arterial arch. In performing both open and endoscopic CTR, the distal extent of an incision placed at the intersection of OKCL and the line along the long axis of the ring finger is a point past which iatrogenic injury to the SPA is possible (Panchal et al., 2010).

A study by Panchal and Trzeciak (2010) show an average distance of $10.2 \mathrm{~mm}$ from the distal extent of our incision to the SPA, theoretically allowing some inherent flexibility in planning of the incision for open and endoscopic CTR. Vasiliadis et al. (2015), showed that the distance between the distal portal of a Chow two-portal endoscopic CTR and the SPA. Using Kaplan's cardinal line and the axis aligned with the third web space, the authors noted an average distance of 10.4 $\mathrm{mm}$ (range $5^{-15} \mathrm{~mm}$ ). There is fat pad around the SPA, at the distal to the transverse carpal ligament. It provides a useful in visualizing carpal ligament release. 


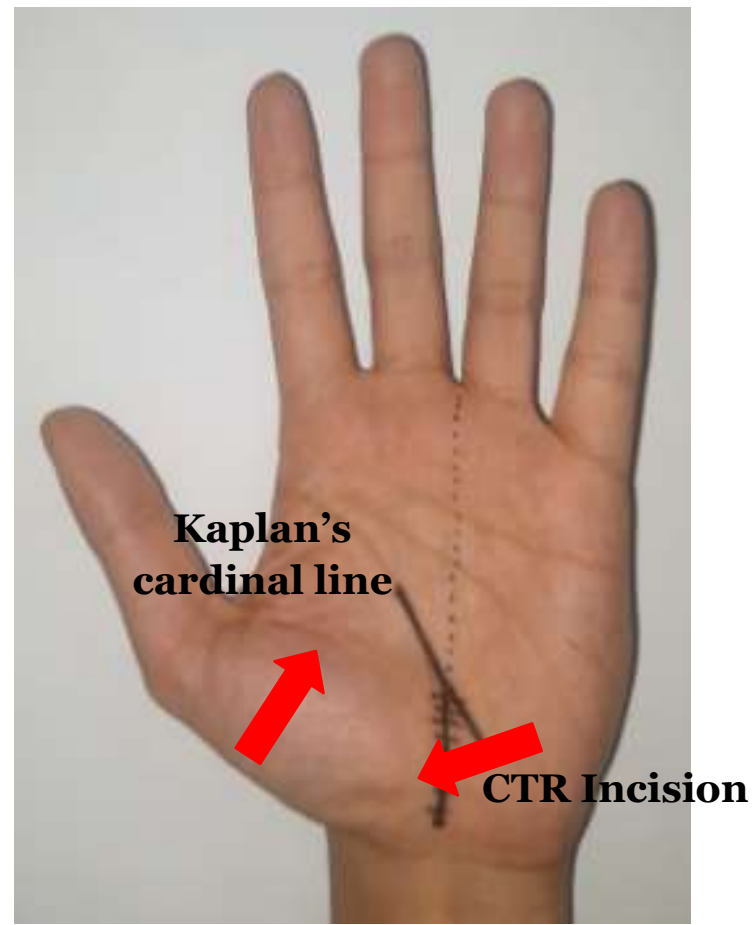

Figure 5. Incision for open carpal tunnel release at the intersection of the proximal extension of the radial border of ring finger with the original description of Kaplan's cardinal line

\section{c. Open Carpal Tunnel Release}

The open technique is the oldest form of techniques in surgical treatment of CTS [26]. OCTR is done by doing a large $4-5 \mathrm{~cm}$ longitudinal incision extending from Kaplan's cardinal line to the wrist crease (Ono et al., 2010; Chammas et al., 2014). The procedure consists of a longitudinal incision at the base of the hand, the incision of the subcutaneous tissue, the superficial palmar fascia and the muscle of the palmar is brevis (Ghasemi-rad et al., 2014). OCTR has been shown to be an effective and relatively safe procedure, and is established as the standard surgical treatment for CTS (Badger et al., 2008; Ono et al., 2010; Khan et al., 2015). OCTR is generally accepted method by surgeon, and reported high success rate with minimal complication (Badger et al., 2008; Kim et al., 2014). This procedure is indicated and feasible for treating CTS with any type of pathology (space occupying lesion, deformity, or revision of previous surgeries) (Kim et al., 2014).
Khan et al. (2014) followed up 100 patients that had been operated to treats their CTS showed functional outcome and satisfaction of the patient was $82 \%$ at 1 month, $94 \%$ at 3 months and $97 \%$ at 6 months (Khan et al., 2015). This study also concludes that OCTR should be offered to patients with moderate to severe CTS symptom. In another study by Badger et al. (2008), a review evaluating outcome of 32 patient that had been undergone OCTR by using The Boston carpal tunnel questionnaire, showed $88 \%$ patients had a significant reduction in the symptom severity score, and $79 \%$ patients had improvement in function status score.

In a prospective study, conducted by Louie et al. (2013), following patients underwent surgery for CTS at minimum 10 years to determine long-term outcome found that most of patients were satisfied with the result, pain and symptom free, and only low rate of reoperation (1.8\%). 


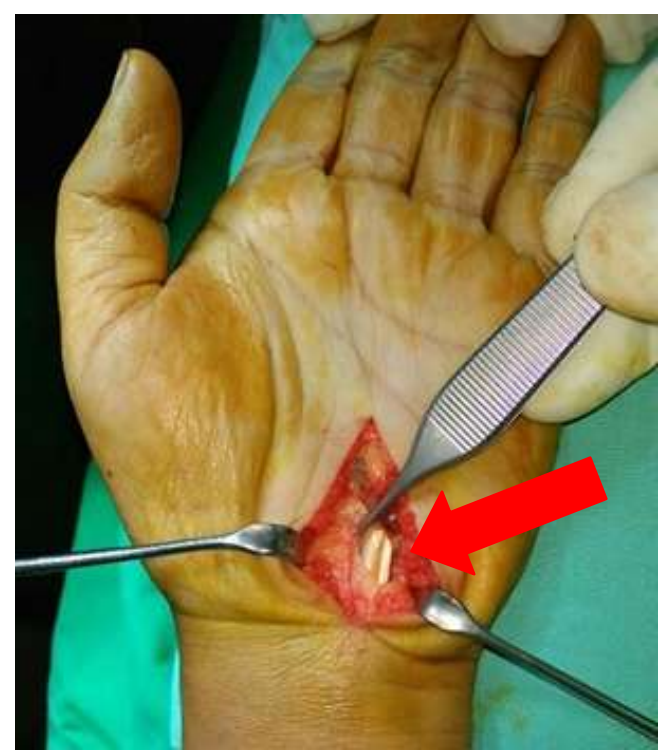

Figure 6. Open Carpal Tunnel Release procedure is shown.

Incision was made extending from Kaplan's cardinal line to wrist crease; align with the radial border of the ring finger. The median nerve can be seen after flexor retinaculum was released under direct vision (arrow)

\section{d. Endoscopic Carpal Tunnel Release}

Endoscopic carpal tunnel release (ECTR) is new technique (Ghasemi-rad et al., 2014; Kim et al., 2014), that was developed and introduced by Okutsu and colleagues at 1986 with single-portal incision, and two portal technique by Chow (Chow, 1989). Okutsu et al. (1989) developed their procedure to visualize the TCL and transected it under endoscopic assistance using special tube like instrument (Okutsu et al. (1989). The single portal technique consists of one single incision at the wrist to release of the TCL, while doubleportal technique consists of two incisions, one at the wrist and one at the palm of the hand (Ghasemi-rad et al., 2014). ECTR was invented to minimalize potential complications of OCTR by using smaller incisions (Ono et al., 2010). ECTR has relatively shorter postoperative period, faster recovery of grip strength, reduced scar tenderness, and allows earlier return to work. Those good outcome are assumed because of preservation of the superficial fascia and adipose tissue over the flexor retinaculum (Ono et al., 2010; Padua et al., 2016).

In a prospective nonrandomized clinical trial, Nazerani et al. (2014), followed 176 patients with CTS who underwent ECTR surgery, 164 cases (93.2\%) had no or very little pain at the one year postoperative visit, and nearly all of the patients reported no relapse of symptoms at the previously mentioned postoperative time point. In another study conducted by Calotta et al. (2017), concluded that ECTR is a safe and effective alternative to OCTR for patients with severe CTS. This study showed from $82 \%$ (32 of 39) of cases treated with ECTR had complete resolution of symptoms compared with $39 \%$ (39 of 99) of cases that underwent OCTR.

In 2013, a meta-analyses study of fifteen randomized controlled trials involving 1,596 hands by Chen et al. (2014), showed that both ECTR and OCTR have a similarity rate in relief of symptom, but ECTR has better functional recovery and earlier return to work (Ono et al., 2010; Sayegh et al., 2015; Padua et al., 2016). In their meta-analyses 
study, Sayegh et al. suggest that ECTR also improved strength during the early postoperative period, and reduce scar tenderness. ECTR has small incision compared with OCTR, leads to less risk of injury to the surrounding tissue. It also has earlier relief of sensory and motor functions than OCTR (Calotta et al., 2014; Sayegh et al., 2015). However, in long-term follow-up, ECTR and OCTR have the same outcome (Sayegh et al., 2015).

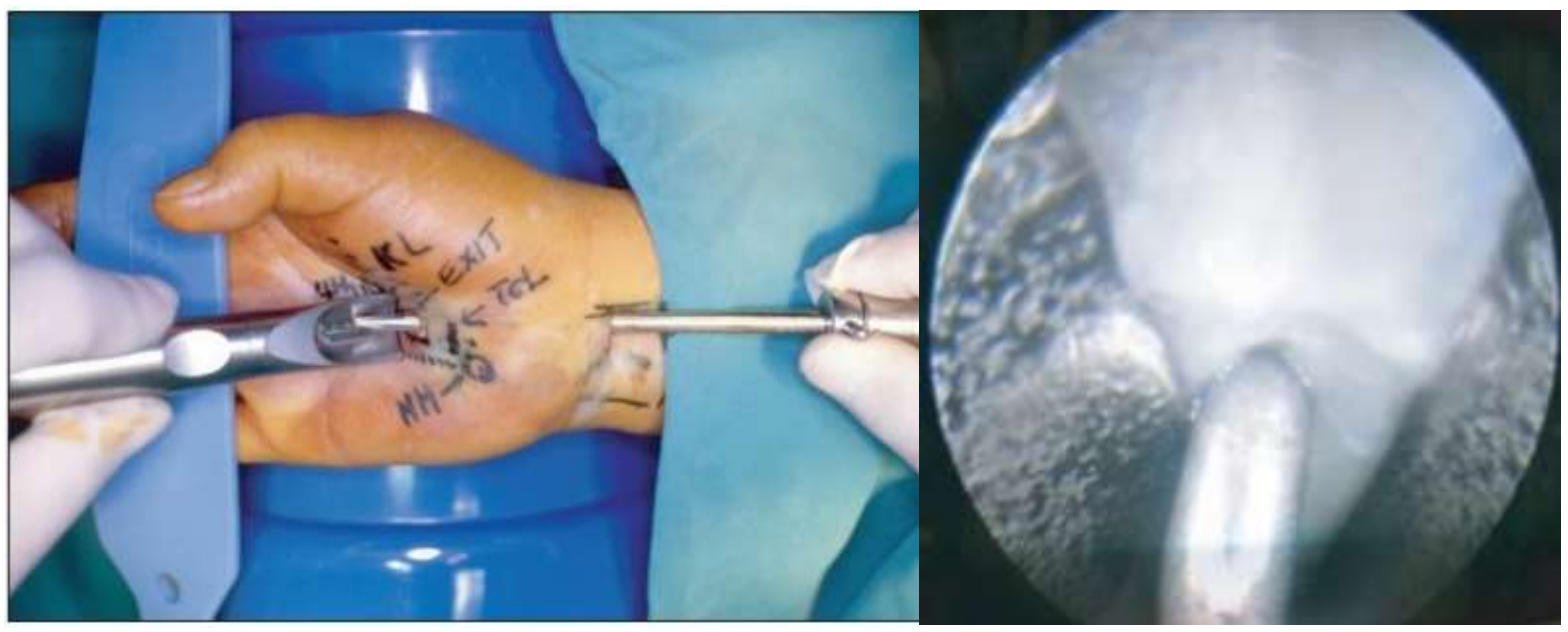

Figure 7. Endoscopic Carpal Tunnel Release, Figure A showing an introduction of endoscopic cannula beneath transverse carpal ligament. Figure B showing undersurface of transverse carpal ligament with a blade dissecting the ligament [3o].

\section{e. Mini-Open Carpal Tunnel Release}

In last several years, many surgeons have developed modification of OCTR, called the short-incision procedure or "mini" open carpal tunnel release (mini-OCTR). The rationale of mini-OCTR is to combine the simplicity and safety of OCTR with the reduced tissue trauma and postoperative morbidity of ECTR by using anopen procedure with short incision (Ono et al., 2010), so it can release the median nerve without endangering important structure that can lead to a complication (Bai et al., 2018). 1$2 \mathrm{~cm}$ long incision is mad in line with radial edge of 4th finger (GülGen et al., 2013; Chammas et al., 2014; Oh et al., 2017). There are several technique incisions for miniOCTR (Chammas et al., 2014; GülGen et al., 2013). Wrist-incision technique is performed with a incision $1 \mathrm{~cm}$ above distal wrist crease. In this method transverse carpal ligament is blindly cut from proximal to distal. The other technique is midpalmar incision; ligament is cut from distal to proximal (GülGen et al., 2013).

The aim of mini OCTR is to minimize the complication of the other method of CTR which are prolonged healing process due to long incision, pillar pain, scar tenderness and sensitivity (GülGen et al., 2013; Ondul et al., 2014; Bai et al., 2018). In a prospective study, conducted by Malliyapa et al., following 22 patient who underwent limited open carpal tunnel release showed an overall improvement in $96.3 \%$ of hands measured by Symptom Severity Score (SSS) and Functional Status Score (FSS) pre- and postoperatively. There was no pillar pain, scar tenderness, and nerve injuries reported in this study (Maliyappa et al., 2014). Bai et al. in their study said that pillar pain is related to the incision, smaller incision, smaller the rate of incidence of pillar pain (Bai et al., 2018). In another study conducted by Ondul et al. 
found that mini palmar skin incision has minor complication, cost effective, and earlier for patients to go back to work, compared to endoscopic methods. There was no formation of hypertrophic sensitive scar tissue and infection at surgery area (GülGen et al., 2013; Ondul et al., 2014). Mini OCTR allow direct visualization of median nerve, reducing risk of nerve injury during procedure (Ondul et al., 2014).

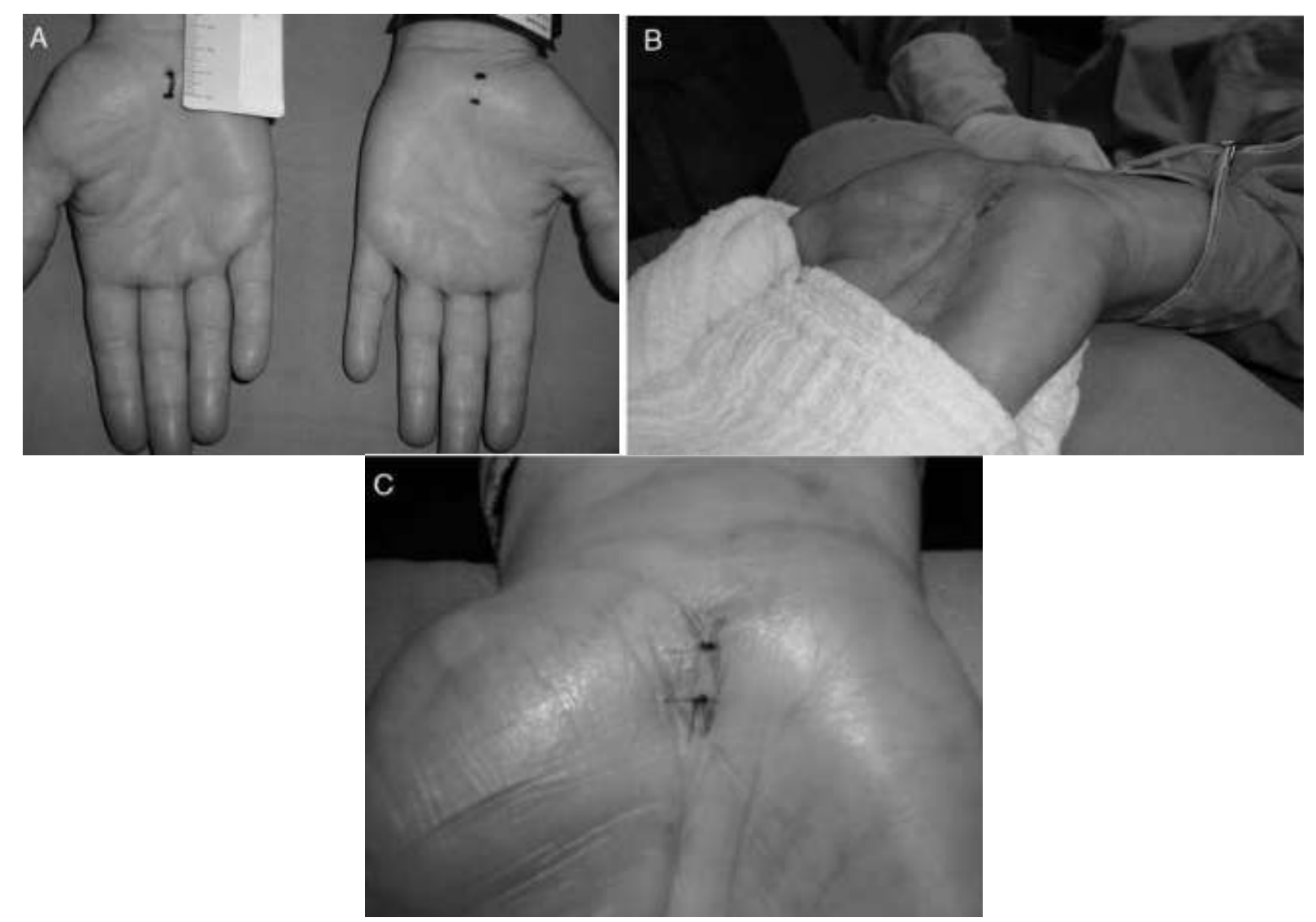

Figure 8. Mini Open Carpal Tunnel Release procedure is shown.

Figure A showing only $1 \mathrm{~cm}$ incision design. Figure $B$ showing patient hand during operation, and Figure $C$ showing post operation condition with only 2 stiches

\begin{abstract}
Complication of Carpal Tunnel Release Surgery

OCTR is the oldest surgical treatment for CTS and has been known to be an effective and relatively safe procedure, and is established as the standard surgical treatment for CTS (Badger et al., 2008; Ono et al. 2010; Chammas et al., 2014; Khan et al., 215). The long incision of conventional carpal tunnel release (OCTR) may result in longer time of healing, higher risk of infection, scar tenderness, and pillar pain may
\end{abstract}

developed after procedure (Boya et al., 2008; GülGen et al., 2013; Murthy et al., 2015).

Pillar pain is deep pain in a regio of thenar or hypothenar, or both. It usually induced by hand grip or by direct pressure or pinching on thenar and hypothenar regions (Boya et al., 2008). Pillar pain and scar tenderness resulted by injured subcutaneous nerve branches during procedure (Boya et al., 2008; Ondul et al., 2014). Even wound infection and wound dehiscence are rare complications, but OCTR has higher rate of post- 
operative infection and wound dehiscence compared to ECTR due to longer skin incision (Ondul et al., 2014; Vasiliadis et al., 2015; Devana et al., 2018). Less invasive procedure was developed such as endoscopic and limited-incision technique in order to minimize complications (Boya et al., 2008).

Several studies has reported that endoscopic carpal tunnel release (ECTR) is as effective as open carpal tunnel release (OCTR) (Chen et al., 2014), even some studies reported ECTR is more superior than OCTR. It has better functional recovery, minimal scar tenderness, and earlier return to work (Ono et al., 2010; Chen et al., 2014; Sayegh and Strauch, 2015; Padua et al., 2016). Even ECTR is known as effective and save procedure, it has its own limitation. In ECTR surgeon have to insert the cannula high pressure carpal tunnel, and it may increase more pressure and give more compression to diseased median nerve. Even there has never been a study that explains how much pressure can be sustained by median nerve, an iatrogenic injury to the median nerve had ever been reported (Uchiyama et al., 2010; Vasiliadis et al., 2015; Zuo et al., 2015). This may lead to a transient neuropraxia which were subsided within several weeks and does not affect the final result of the procedure (Vasiliadis et al., 2015; Zuo et al., 2015). Complication risk of ECTR also arises from lack of visualization of surrounding soft tissue, so that neurovascular may be injured during procedure (Vasiliadis et al., 2015; Paryavi et al., 2016).

Many study had conclude that mini open carpal tunnel release (mini-OCTR) has superiority compared to two other surgical approaches. It is effective in symptom relief, low rate of complications, cost effective, and good in cosmetic (GülGen et al., 2013; Ondul et al., 2014; Oh et al., 2017; Bai et al., 2018). Even though mini OCTR has several advantages compared to OCTR and ECTR, there are chances of neurovascular injury or incomplete release of transverse carpal ligament during surgery (Bai et al., 2018). Kang et al. (2013), in their prospective study comparing ECTR with Mini OCTR reported that in 3 months postoperative follow up, patients were preferred endoscopic technique. The reason for not preferring mini-OCTR was due to scar or pillar pain.

Based on the results of this study, it can conclude that some non-operative treatments, like splinting, corticosteroid injection, exercise, and oral medication are still widely used and effective to reduce symptoms of CTS. However, non-operative treatments only effective for mild to moderate CTS and the recurrence rate are high. For operative treatment, OCTR, ECTR, and Mini-OCTR are reviewed. OCTR still become a standard treatment and effective in release symptom of severe CTS. OCTR is a simple and safe procedure because it allows direct visualization to the nerve. OCTR procedure provides some complications, such as long wound healing and hand functions recovery due to big incision, even it ends up with good clinical outcome. ECTR is still debatable on fact that surgeons have to insert cannula into already high pressured tunnel, which can give more harm to the nerve. Despite that fact, it is an useful technique for releasing pressure in carpal tunnel. However, there is still lack of data to support ECTR provides superior clinical results compared OCTR in terms of fewer complication and early recovery of hand function. Mini-OCTR is modification of OCTR with much smaller incision size. The idea is to reduce surrounding soft tissue trauma and postoperative complication. Compared to OCTR and ECTR, MiniOCTR is superior in symptom relief, no pillar pain or scar tenderness, has minor complication, and cost effective. 


\section{AUTHOR CONTRIBUTION}

Pamudji Utomo, Wan Adi Surya, Seti Aji Hadinoto, and Tito Sumarwoto contributed to the design and implementation of the study. All authors discussed the results and contributed to the final manuscript.

\section{CONFLICT OF INTEREST}

The authors declare there was no conflict of interest.

FUNDING AND SPONSORSHIP

There was no external funding.

\section{ACKNOWLEDGEMENT}

We would like to show our gratitude to the Department of Orthopaedics and Traumatology, Prof. Dr. R. Soeharso Orthopaedics Hospital, Surakarta, Central Java, that support and give permission for this study.

\section{REFERENCE}

Ahmed OF, Elkharbotly AM, Taha N, Bekheet $A B$ (2017). Treatment of mild to moderate carpal tunnel syndrome in patients with diabetic neuropathy using low level laser therapy versus ultrasound controlled comparative study. BBA Clin. 8: 43-47. https://doi.org/10.1016/j.bbacli.2017.07.001

American Academy of Orthopaedic Surgeons Work Group Panel (2007). Clinical guidelines on diagnosis of carpal tunnel syndrome. CRC Press.

Andrian, Lailiyya N, Novitri (2017). Carpal tunnel syndrome prevalence and characteristics among administrative staff at Dr.Hasan Sadikin General Hospital Bandung. Althea Med J. 4(2):192-6. Doi: 10.1585o/amj.v4n2.1077

Ashworth NL (2016). Carpal tunnel syndrome. Am Fam Physician. 94(10): 830-1. https://www.aafp.org/afp/2016/1115/p830.html

Atroshi I, Flondell M, Hofer M, Ranstam J (2013). Methylprednisolone injections for the carpal tunnel syndrome: a randomized, placebo-controlled trial. Ann Intern Med. 159(5): 309-17. https://doi.org/10.7326/ooo3-4819-159-5-201309030-00004

Badger SA, O'Donnell ME, Sherigar JM, Connolly P, Spence RAJ (2008). Open Carpal Tunnel Release - still a safe and effective operation. Ulster Med J. 77 (1): 22-24. https://www.ncbi.nlm.nih.gov/pmc/articles/PMC2397012/

Bai J, Kong L, Zhao H, Yu K, Zhang B, Zhang $Z$, Tian D (2018). Carpal tunnel release with a new mini-incision approach versus a conventional approach, a retrospective cohort study, Int J Surg. 52: 105-109. https://doi.org/10.1016/j.ijsu.2018.02.033

Blazar PE, Floyd E, Han CH, Rozental TD, Earp BE (2015). Prognostic indicators for recurrent symptoms after a single corticosteroid injection for carpal tunnel syndrome. J Bone Joint Surg Am. 97(19): 1563-70. https://doi.org/10.2106/JBJS.N.01162

Blom A, Warwick D, Whitehouse M (2017). Apley and Solomon's System of Orthopaedic and Trauma, 1oth Edition (2017). London: Arnold

Boya H, Ozcan O, Oztekin HH (2008). Long Term Complication of Carpal Tunnel Release. Muscle Nerve, 38(5): 14431446. https://doi.org/10.1002/mus.21068

Calotta NA, Lopez J, Deune EG (2017). Improved surgical outcomes with endoscopic carpal tunnel release in patients with severe median neuropathy. Hand. 12(3): 252 -257. https://doi.org/10.1177/1558944716661995

Carlson H, Colbert A, Frydl J, Arnall E, Elliot M, Carlson N (2010). Current options for nonsurgical management of carpal tunnel syndrome. Int J Clin Rheumtol. 
5(1): 129-142. https://doi.org/10.2217/IJR.09.63

Chammas M, Boretto J, Burmann LM, Ramos RM, dos Santos Neto FC, Silva JB (2014). Síndrome do túnel do carpo - Parte I (anatomia, fisiologia, etiologia e diagnóstico). Rev Bras Ortop. 49(5):429-36. https://doi.org/10.1016/j.rboe.2014.08.001

Chang YW, Hsieh SF, Horng YS, Chen HL, Lee KC, Horng YS (2014). Comparative effectiveness of ultrasound and paraffin therapy in patients with carpal tunnel syndrome: a randomized trial. BMC Musculoskel Disord. 15: 399. https://dx.doi.org/10.1186\%2F1471-2474-15399

Chen L, Duan X, Huang X, Lv J, Peng K, Xiang Z (2014). Effectiveness and safety of endoscopic versus open carpal tunnel decompression. Arch Orthop Trauma Surg. 134(4): 585-593. https://doi.org/10.1007/s00402-013-1898-Z Chen PC, Chuang $\mathrm{CH}$, Tu YK, Bai CH, Chen CF, Liaw MY (2015). A Bayesian network meta-analysis: Comparing the clinical effectiveness of local corticosteroid injections using different treatment strategies for carpal tunnel syndrome. BMC Musculoskelet Disord. 16: 363. https://doi.org/10.1186/s12891015-0815-8

Chesterton LS, Blagojevic-Bucknall M, Burton C, Dziedzic KS, Davenport G, Jowett SM, Myers HL, et al. (2018). The clinical and cost-effectiveness of corticosteroid injection versus night splints for carpal tunnel syndrome (INSTINCTS trial): an open-label, parallel group, randomised controlled trial. Lancet. 392(10156): 1423-33. https://doi.org/10.1016/So140-6736(18)31572-1

Chow JCY (1989). Endoscopic release of the carpal ligament: a new technique for carpal tunnel syndrome. Arthroscopy: The Journal of Arthroscopic \& Related Surgery. 5(1):19-24. https://doi.org/10.1016/0749-8063(89)90085-6

Demicray E, Civeilek E, Cansever T, Kabatas $\mathrm{S}$, Yilma C (2011). Anatomic variations of the median nerve in the carpal tunnel: A brief review of the literature. Turkish Neurosurger. 21(3): 388-396. https://doi.org/10.5137/10195149.JTN.3073-10.1

Devana SK, Jensen AR, Yamaguchi KT, D'Oro A, Buser Z, Wang JC, Petrigliano FA, Dowd C (2018). Trends and complications in open versus endoscopic carpal tunnel release in private payer and medicare patient populations. HAND. 14(4): 455-461. https://doi.org/10.1177/1558944717751196

Ghasemi-rad M, Nosair E, Vegh A, Mohammadi A, Akkad A, Lesha E, Mohammadi MH, Sayed D, Davarian A, Maleki-Miyandoab T, Hasan H (2014). A handy review of carpal tunnel syndrome: From anatomy to diagnosis and treatment. World J Radiol, 6(6): 28430o. https://dx.doi.org/10.4329\%2Fwjr.v6.i6.284

GülGen E, Ak H, EvcJlJ G, Balbaloglu O, Sösüncü E (2013). A retrospective comparison of conventional versus transverse mini-incision technique for carpal tunnel release. ISRN Neurol, 721830. https://dx.doi.org/10.1155\%2F2013\%2 F721830

Halac G, Demir S, Yucel H, Niftaliyev E, Kocaman G, Duruyen H, KenDirli T, Asil T (2015). Splinting is effective for night-only symptomatic carpal tunnel syndrome patients. J Phys Ther Sci. 27(4): 993-996. https://doi.org/10.1589/jpts.27.993

Ibrahim I, Khan WS, Goddard N, Smitham P (2012). Carpal Tunnel Syndrome: A Review of the Recent Literature. Open 
Utomo et al./ Management of carpal tunnel syndrome

Orthop J. 6(1): 69-76. https://doi.org/10.2174/1874325001206010069

Kang HJ, Koh IH, TJ Lee, Choi YR (2013). Endoscopic carpal tunnel release is preferred over mini-open despite similar outcome: A randomized trial. Clin Orthop Relat Res. 471(5): 1548-1554. https://doi.org/10.1007/s11999-012-2666-z

Khan AA, Ali H, Ali K, Muhammad G, Rashid B, Gul N, Zadran KK, et al. (2015). Outcome of Open Carpal Tunnel Surgery. J Ayub Med Coll Abbottabad. 27(3). https://jamc.ayubmed.edu.pk/index.php/jamc/article/view/302

Kim PT, Lee HJ, Kim TG, Jeon IH (2014). Current Approaches for Carpal Tunnel Syndrome. Clin Orthop Surg. 6(3): 253-257. https://dx.doi.org/10.4055\%2Fcios.2014.6.3.253

Lee JY, Park Y, Park KD, Lee JK, Lim OK (2014). Effectiveness of ultrasoundguided carpal tunnel injection using inplane ulnar approach: a prospective, randomized, single-blinded study. Medicine (Baltimore). 93(29): e350. https://doi.org/10.1097/MD.ooooooo o00000350

Maliyappa CC, George MA, Al-Marboi BK (2014). Outcome analysis of limited open carpal tunnel release: A prospective study. J Orthop Traumatol Rehabi. 7(2): 161-4. Doi: 10.4103/0975-7341.165323 .

Martins RS, Siqueira MG (2017). Conservative management of carpal tunnel syndrome. Arq. Neuro-Psiquiatr. 75(11). https://doi.org/10.1590/0004-282X20170152.

Murthy PG, Goljan P, Mendez G, Jacoby SM, Shin EK, Osterma AL (2015). Miniopen versus extended open release for severe carpal tunnel syndrome. Hand (NY). 10(1):34-9. https://doi.org/10.1007/s11552-014-9650-X
Nazerani S, Motamedi MHK, Nazerani T, Saraii A, Keramati MR (2014). Endoscopic Carpal Tunnel Release: A 5-Year Experience. Trauma Mon.19(4): e18058. https://doi.org/10.5812/traumamon. 18058

Oh WT, Kang HJ, Koh IH, Jang JY, Choi YR (2017). Morphologic change of nerve and symptom relief are similar after miniincision and endoscopic carpal tunnel release: a randomized trial. BMC Musculoskeletal Disorders. 18(1): 65. https://doi.org/10.1186/s12891-017-1438-z

Okutsu I, Ninomiya S, Takatori Y, Ugawa Y (1989). Endoscopic management of carpal tunnel syndrome. Arthroscopy. 5(1):11-8. https://doi.org/10.1016/o749-8063(89)90084-4

Ondul S, Durmus M, K Ertilav (2014). Open carpal tunnel surgery through a minipalmar skin incision: A retrospective analysis of 500 patients and 590 hands. Neurosurg Q. 24(1): 5-8. Doi: 10.1097/WNQ.obo13e31828c70c8

Ono S, Clapham PJ, Chung KC (2010). Optimal management of carpal tunnel syndrome. Int J Gen Med. 3: 255-261. https://doi.org/10.2147/ijgm.s7682

Padua L, Coraci D, Erra C, Pazzaglia C, Paolasso I, Loreti C, Caliandro P, HobsonWebb LB (2016). Carpal tunnel syndrome: clinical features, diagnosis, and management. Lancet Neurol. 15(12): 1273-84. https://doi.org/10.1016/S1474-4422(16)30231-9

Page MJ, O’Connor D, Pitt V, Massy-Westropp $N$ (2012). Exercise and mobilisation interventions for carpal tunnel syndrome. Cochrane Database Syst Rev. 13(6): CDoo9899. https://doi.org/10.1002/14651858.CDoo9899

Paget J (2007). The first description of carpal tunnel syndrome. J Hand Surg 
Eur. 32(2): 195-7. https://doi.org/10.1016/J.JHSB.2006.12.010

Panchal AP, Trzeciak MA (2010). The clinical application of Kaplan's cardinal lineas a surface marker for the superficial palmar arch. Hand. 5(2): 155-159. https://dx.doi.org/10.1007\%2Fs11552-0099229-O

Paryavi E, Zimmerman RM, Means KR (2016). Endoscopic compared with open operative treatment of carpal tunnel syndrome. JBJS Rev. 4(6):e2. https://doi.org/10.2106/JBJS.RVW.15. 00071

Sabet R, Rahmanian K, Jahromi AS, Madani A (2017). Analgesic effect of gabapentin in patients with carpal tunnel syndrome. Journal of Applied Pharmaceutical Science. 7(6): 079-082. Doi: 10.7324/JAPS.2017.70611

Sayegh ET, Strauch RJ (2015). Open versus endoscopic carpal tunnel release: A meta-analysis of randomized controlled trials. Clin Orthop Relat Res. 473(3): 1120-1132. https://dx.doi.org/10.1007\%2Fs11999-014-3835-Z

Seiler JG (2002). Essentials of Hand Surgery: American Society for Surgery of the Hand. Lippincott Williams \& Wilkins.

Talebi M, Andalib S, Bakhti S, Ayromlou H, Aghili A, Talebi A (2013). Effect of vitamin $\mathrm{B} 6$ on clinical symptoms and electrodiagnostic results of patients with carpal tunnel syndrome. Advanced Pharmaceutical Bulletin. 3(2): 283288. https://doi.org/10.5681/apb.2013.046

Uchiyama S, Uitsobo T, Nakamura K, Kato $\mathrm{H}$, Sutomi T, Momose T (2010). Current concepts of carpal tunnel syndrome: pathophysiology, treatment, and evaluation. J Orthop Sci. 15(1): 1-13. https://doi.org/10.1007/s00776-0091416-X

Vasiliadis HS, Nikolakopoulou A, Shrier I, Lunn MP, Brassington R, Scholten RJP, et al. (2015). Endoscopic and open release similarly safe for the treatment of carpal tunnel syndrome. A Systematic Review and Meta-Analysis. PLoS ONE 10(12): e0143683. doi:10.1371/journal.pone.0143683

Wipperman J, Goerl K (2015). Carpal tunnel syndrome: Diagnosis and management. Am Fam Physician. 94(12): 993-999. https://www.aafp.org/afp/2016/1215/ p993.html

Zuo D, Zhou Z, Wang W, Liao Y, Zheng L, Hua Y, Cai Z (2015). Endoscopic versus open carpal tunnel release for idiopathic carpal tunnel syndrome: a metaanalysis of randomized controlled trials. J Orthop Surg Res. 10: 12. https://dx.doi.org/10.1186\%2Fs13018-0140148-6 